\title{
Time Series Analysis of Air Pollutants for Karabük Province
}

\author{
Ali $C A N$ \\ Karabuk University, Engineering Faculty, Mechanical Engineering Department, Balıklar Kayası Mevkii, Karabük, 78100, Turkey
}

\begin{abstract}
The air is polluted and the atmospheric pollution has becoming a great problem for human beings due to the high rate consumption of energy. Most of the scientists dealing with the air pollution state that the first reason of all environmental problems is the population increase. Depending on population, the high consumption of energy (including heating purposes, electricity production, transportation and industries) agricultural activities, waste disposal and the pressure for destroying forest areas create air pollution problem. The atmosphere is polluted and the concentrations of pollutants have increased tremendously. Karabük Province is one of the famous provinces of heavy industries. There are 3 air quality measurement stations. In this study, the last 2 years hourly and daily air pollutants $\left(\mathrm{PM} 10, \mathrm{SO}_{2}, \mathrm{NO}, \mathrm{NO}_{\mathrm{x}}\right.$, $\mathrm{NO}_{2}, \mathrm{O}_{3}$ and $\mathrm{CO}$ ) were studied as a time series by using graphical and statistical approaches. The results were considered seasonally and annually. The meteorological condition is also very effective in atmospheric pollution. Moreover, the industrial production and consumption of energy are also high pressure on Karabük province. The concentrations in each station are also showing different characteristics during two years' period. The highest concentrations (such as $\mathrm{PM} 10, \mathrm{SO}_{2}, \mathrm{NO}, \mathrm{NO}_{\mathrm{x}}$ ) are, as usual, seen in winter season due to industrial usage of energy for production and household consumption of energy for heating. However, for $\mathrm{O}_{3}$, the highest concentration is observed in summer season, because the atmospheric ozone trend is supposed to show an opposite trend compared with NO due to photochemical reaction with these gases. For $\mathrm{CO}$, the maximum concentration is recorded as $4779 \mu \mathrm{g} / \mathrm{m} 3$ in august in 2015 . The analyses of data have shown that, the atmosphere is polluted highly with $\mathrm{PM} 10, \mathrm{SO}_{2}, \mathrm{NO}, \mathrm{NO}_{\mathrm{x}}, \mathrm{NO}_{2}$, and $\mathrm{CO}$ during winter season. The households are very effective using high coal for heating purposes in Karabük Province.
\end{abstract}

Keywords: Air Pollutant Concentration, Time Series Analyses, Atmospheric Pollution

\section{INTRODUCTION}

The air pollution data are always evaluated as time series. Time series are mainly used to estimate missing data or used to determine trend for future estimation [1]. In the air pollution, the future scenarios are always important to tackle with this global scale problem [2]. The statistical, mathematical or graphical approach can be used for data analyses $[6,11]$. The biggest problem in time series analyses is the missing data. In a study resulted by Junger and Leon [7], the complete data analysis will yielding satisfactory results regardless of the generating mechanism of the missing data if the amount of missing data is equal or lower than $5 \%$, whereas the validity began to decline when the proportion of missing values are exceeding $10 \%$. The increases of missing data over $10 \%$ are always resulted in some assumptions in the analyses. And the assumptions mean that the decrease in the precision [5].

The air pollutant in the atmosphere is increasing and the local studies have shown that the effect of long-range air transport is varying due to the different aspect in the regions. The meteorology, geographical aspect, persistence in the air, climate and seasons have big effect in the air pollution $[9,12,13]$. In another words, the time series are the sequence of many segments and environment $[4,8]$.

The main aim of this analysis is to put the characteristic of the data. To emphasize the trend and statistical analyses are mainly the complementary of this kind of studies. According to the results, the ordering of the data is natural. Time is selected as the depending variable. Finding the changes and fluctuations of air pollutants at local state is aimed. The main difficulty is the missing data due to equipment failure for some days during the study years.

\section{Materials and Methods}

Study Area: Karabük Province is one of the famous provinces of heavy industries. The map is prepared by using a GIS programme (Fig.1). In this study, the last 2 years air pollutants were studied. There are 3 air quality measurement stations. Because of private confidentiality, the places of air quality measurement stations are not given in this study. In one station, only $\mathrm{SO}_{2}$ and PM10 are measured, the other pollutants are not measured for the study period. Therefore, the daily averages of pollutants for Karabük were calculated according to measured parameters.

* Corresponding author: $\underline{\text { alican} @ \text {,karabuk.edu.tr }}$ 


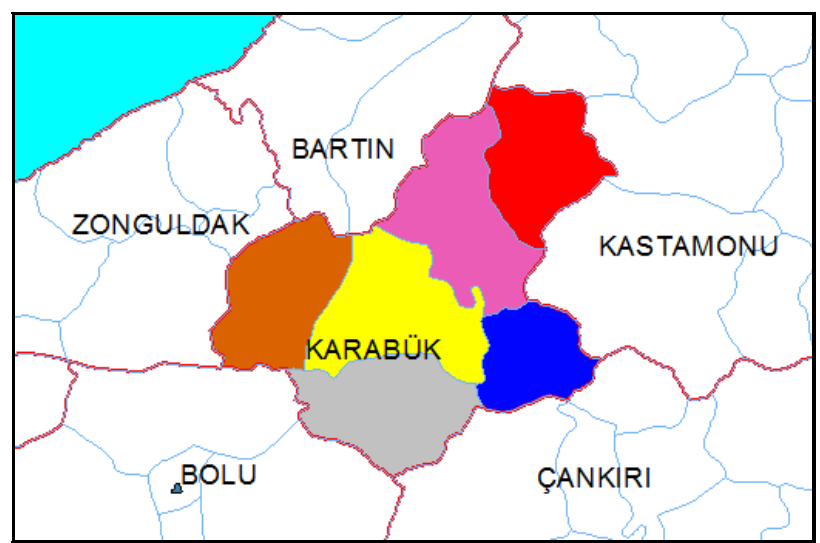

Fig. 1. The Karabük Province

Data: The data is gathered from the Ministry of Environment and Urbanization Air Quality Monitoring Network (AQMN) web page [10]. The last 2 years hourly air pollutants (PM10, $\mathrm{SO}_{2}, \mathrm{NO}, \mathrm{NO}_{\mathrm{x}}, \mathrm{NO}_{2}, \mathrm{O}_{3}$ and $\mathrm{CO}$ ) were collected and analysed.

Method: The air pollutants are generally passed two evolutionary stages. The first one is the quantification and second one is qualification according to the air standards [2, 3]. Within this study, the pollutant data is analysed by graphical and statistical approaches. The daily average data of three stations was used. In the first part of study (graphical approach), the annual trend of data was determined. In order to see the trend, a moving averages were also calculated and inserted in the graph. In statistical analyses, the annual minimum, maximum and averages of the pollutants were calculated as supplementary information.

\section{Results and Discussion}

The time series analyses have shown that the pollutant is fluctuating throughout the years. In winter season the concentrations of air pollutant is increasing and during the spring and summer time, the average concentration is lower except for ozone. The situation is just opposite for atmospheric ozone concentration, which is higher during the summer time. By the way, the highest missing data was seen for 2015 data for $\mathrm{NO}, \mathrm{NO}_{\mathrm{x}}, \mathrm{NO}_{2}, \mathrm{O}_{3}$ and $\mathrm{CO}$, but even the lack of many measurements in 2015, the missing ratio is not higher than $10 \%$. Therefore the data is accepted as precise and it reflects the situation of Karabük Province truly.

If the PM10 graph (Fig.2) is examined, the maximum concentrations are determined in the winter season with values $307 \mu \mathrm{g} / \mathrm{m}^{3}$ in 2014 and $276 \mu \mathrm{g} / \mathrm{m}^{3}$ in 2015 . These two values are higher than EPA criteria. It means it is very hazardous for human beings. On the contrary, the PM10 concentration in summer is always lower than 100 $\mu \mathrm{g} / \mathrm{m}^{3}$.

According to the moving averages, there is a decline trend between the winter and autumn seasons. it can be stated that the atmospheric temperature is very affective for the pollutant PM10.

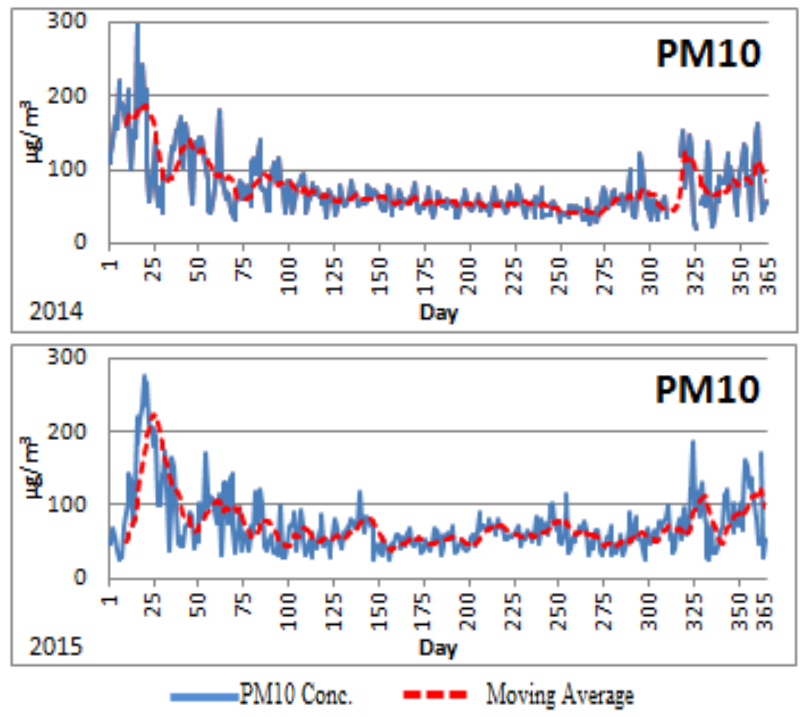

Fig. 2. The PM10 concentration in 2014 and 2015

The trend of $\mathrm{SO}_{2}$ concentration is also very similar to the PM10 graph in 2014. However, it is not the case for 2015, especially in December 2015, the $\mathrm{SO}_{2}$ concentration is increasing considerably and reach the highest value, which is $298 \mu \mathrm{g} / \mathrm{m}^{3}$ (Fig.3), in this month.
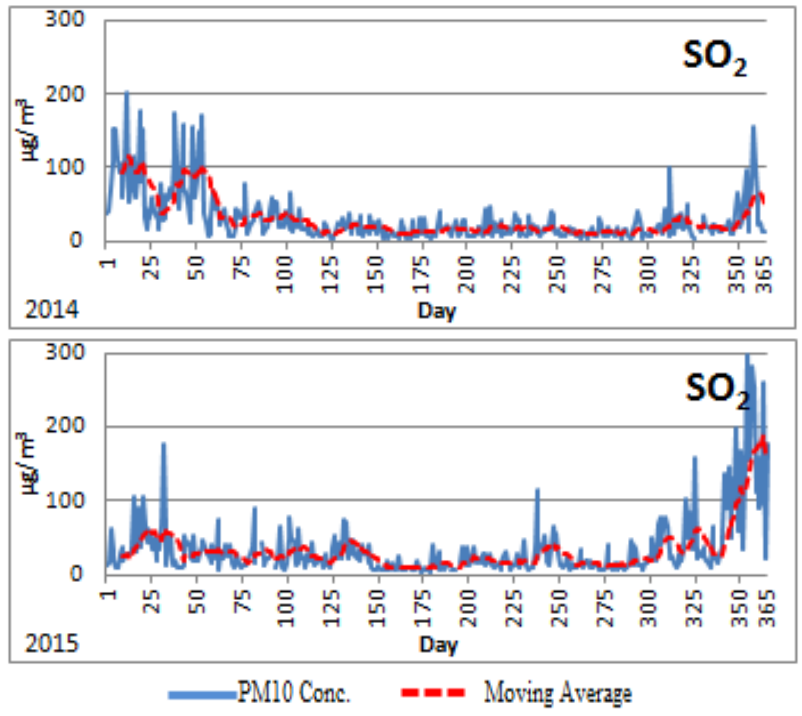

Fig. 3. The $\mathrm{SO}_{2}$ concentration in 2014 and 2015

The figures of $\mathrm{NO}, \mathrm{NO}_{\mathrm{x}}$ and $\mathrm{NO}_{2}$ concentrations are showing different characteristics. For $\mathrm{NO}$ and $\mathrm{NO}_{\mathrm{x}}$, the concentrations are showing the same trend during study period. There is a sharp increase after late august in 2015.

The highest $\mathrm{NO}$ and $\mathrm{NO}_{\mathrm{x}}$ values are determined during this period with respective values 673 and $745 \mu \mathrm{g} / \mathrm{m}^{3}$ which are also very high according to the EPA criteria (Fig.4 and Fig.5). 

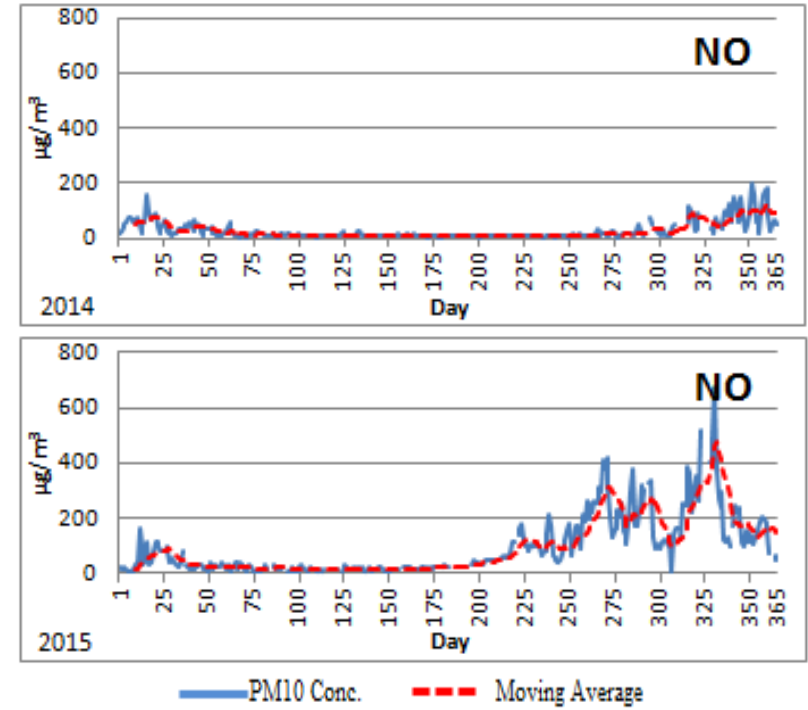

Fig. 4. The NO concentration in 2014 and 2015
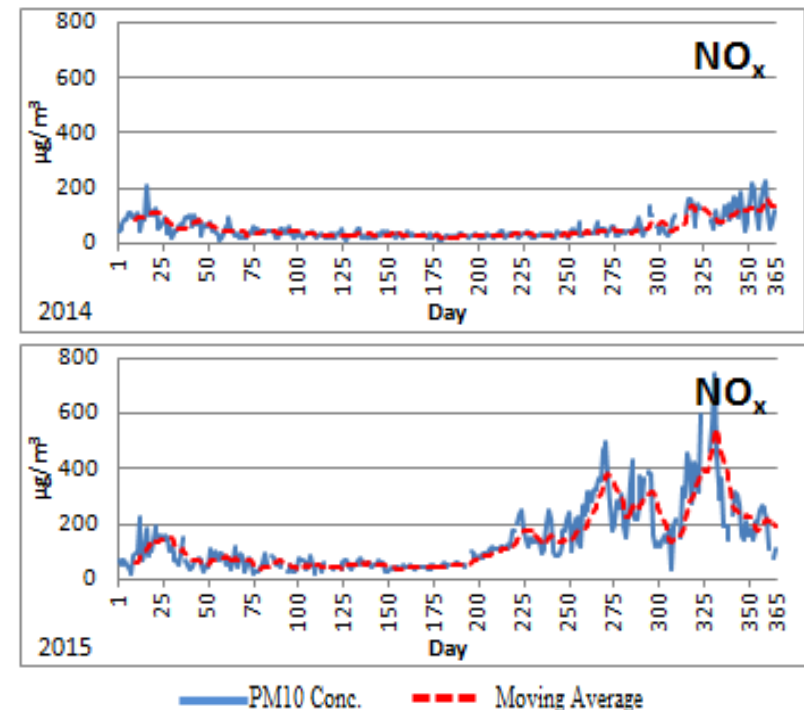

Fig. 5. The $\mathrm{NO}_{\mathrm{X}}$ concentration in 2014 and 2015

The $\mathrm{NO}_{2}$ concentration in 2015 is increasing and the concentration increases on the figure is considerable. The $\mathrm{NO}_{2}$ concentrations in 2015 are about twice that in 2014 (Fig. 6).

During day time, photochemical reaction $\mathrm{NO}$ into $\mathrm{NO}_{2}$ is always decreasing ozone concentrations in the atmosphere. Therefore, the atmospheric ozone trend is supposed to show an opposite fluctuation compared with NO. On the other hand, the photolysis of $\mathrm{NO}_{2}$ by a photons forms $\mathrm{NO}$ and $\mathrm{O}_{3}$. It means, the $\mathrm{NO}-\mathrm{NO}_{2}$ cycle starts again [2].

In figure 7, there is an opposite trend compared to the $\mathrm{NO}$ graph. Then, the $\mathrm{O}_{3}$ concentration graph is showing a sharp increase after winter in 2015.

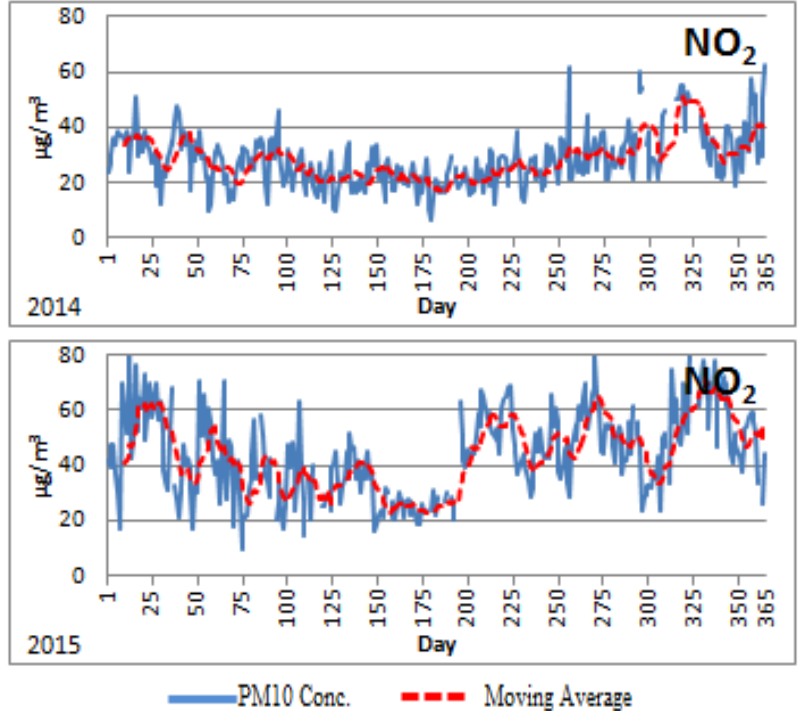

Fig. 6. The $\mathrm{NO}_{2}$ concentration in 2014 and 2015
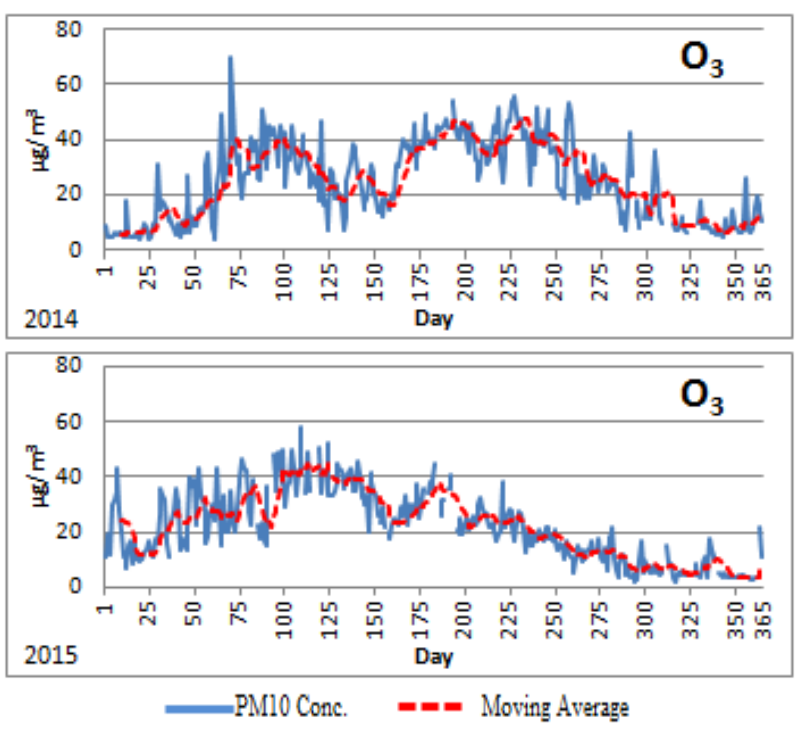

Fig. 7. The $\mathrm{O}_{3}$ concentration in 2014 and 2015

The air quality level for $\mathrm{CO}$ is varying tremendously between $74 \mu \mathrm{g} / \mathrm{m}^{3}$ to $4779 \mu \mathrm{g} / \mathrm{m}^{3}$. The inefficient burning, which results $\mathrm{CO}$ emission, is very dangerous and it will cause death if $\mathrm{CO}$ exposure is continues due to increasing concentration in atmosphere.

The EPA criteria are also exceeded for this pollutant on some days. The concentration of $\mathrm{CO}$ is increasing during winter season according to the figure. The annual average for this gases is around 900-950 $\mu \mathrm{g} / \mathrm{m}^{3}$. Moreover, in 2014, the concentration of $\mathrm{CO}$ is higher than that in 2015 (Fig.8).

In statistical analyses, the annual minimum, maximum and averages of the pollutants were also calculated for series. 


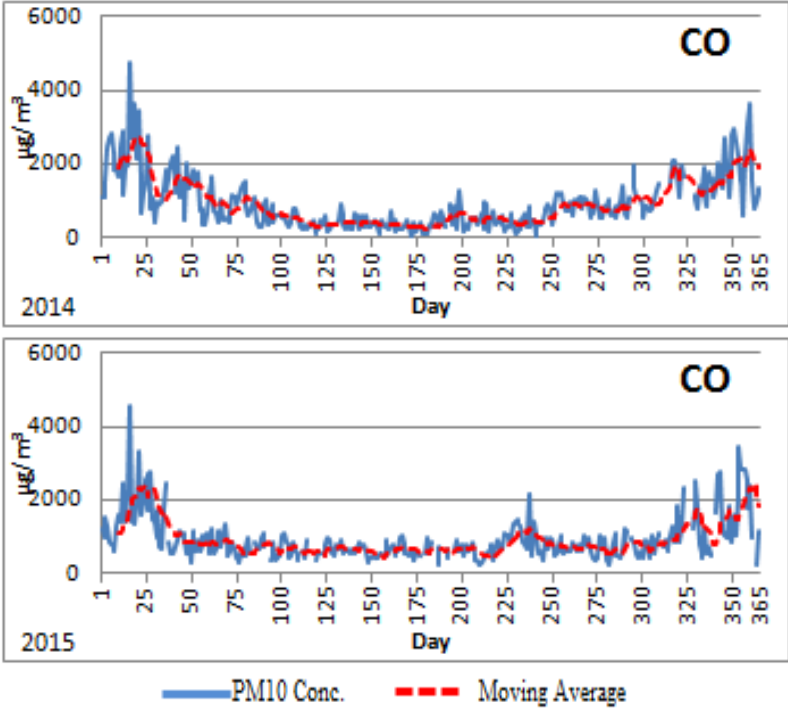

Fig. 8. The CO concentration in 2014 and 2015

The main difficulty is the missing data due to equipment failure for short period. Moreover, the complementary table (Tab. 1) is given below to support the findings.

Tab. 1. The data analysis in 2014 and 2015

\begin{tabular}{lccccccc}
\hline \multicolumn{1}{c}{2014} & $\mathrm{PM} 10$ & $\mathrm{SO}_{2}$ & $\mathrm{NO}$ & $\mathrm{NO}_{\mathrm{x}}$ & $\mathrm{NO}_{2}$ & $\mathrm{O}_{3}$ & $\mathrm{CO}$ \\
\hline \hline Missing Data (\%) & 2,5 & 0,5 & 3,6 & 3,6 & 3,6 & 3,6 & 3,6 \\
Average & 75 & 31 & 26 & 54 & 28 & 25 & 941 \\
Mimimum & 21 & 4 & 3 & 10 & 7 & 4 & 74 \\
Maximum & 307 & 203 & 196 & 225 & 63 & 70 & 4779 \\
\hline \multicolumn{1}{c}{2015} & & & & & & & \\
\hline \hline Missing Data (\%) & 0,3 & 2,2 & 8,8 & 8,8 & 8,8 & 8,2 & 8,2 \\
Average & 73 & 34 & 95 & 139 & 44 & 22 & 923 \\
Mimimum & 25 & 4 & 5 & 18 & 10 & 2 & 223 \\
Maximum & 276 & 298 & 673 & 745 & 86 & 58 & 4587 \\
\hline
\end{tabular}

The pollutants mentioned above are mostly created by the people living in Karabük province. Therefore, the solution for this problem will also be founded by the same people living in this city. With small actions such as; changing coal into natural gas, controlled used of fertilizers ending with atmospheric deposition of nitrogen, and use electrical furnaces instead of coal furnace in industries will comparable change the atmosphere in a short time. The geological aspect is also not permitting the pollutants transfer from local area of Karabük. Moreover, the wind is not powerful for the good dispersion in the atmosphere. Shortly, the air quality data of Karabük province is showing that the air is polluted as in crowded cities and the pollution level is not considered as healthful.

\section{Conclusion}

The highest concentrations (such as PM10, $\mathrm{SO}_{2}, \mathrm{NO}$, $\mathrm{NO}_{\mathrm{x}} \mathrm{NO}_{2}, \mathrm{CO}$ ) are, as usual, seen in winter season. It means household burning is very affective on the atmosphere. However, for $\mathrm{O}_{3}$, the highest concentration is observed in summer season, because the atmospheric ozone trend is supposed to show an opposite fluctuation compared with NO due to photochemical reaction. For $\mathrm{CO}$, the maximum concentration is recorded as 4779 $\mu \mathrm{g} / \mathrm{m}^{3}$ in august in 2015. The atmosphere is polluted and the high anthropogenic emissions are created in Karabük province. Therefore, the solution for this problem will also be founded by the same people living in this city. With applicable actions such as; changing coal into natural gas and use electrical furnaces instead of coal furnace in industries will change the atmosphere in this city comparably in a short time.

\section{References}

1. Alier M., Tauler R., 2013. Multivariate Curve Resolution of incomplete data multisets. Chemometrics and Intelligent Laboratory Systems 127 (2013).p.17-28.

2. Boubel R.A., Fox D.L., Turner D.B., Stern A.C.,1994. Fundamentals of Air Pollution - Academic Press, Third Addition, P.41-59,72-74.

3. Cooper C. D., Alley F.C, 2002. Air Pollution Control-A design Approach.p.58.63.

4. Dirgawati M, Heyworth J. S., Wheeler A.J., McCaul K.A., D.Black., Boeyen J., Cope M., Yeap B.B., Nieuwenhuijsen M., Brunekreef B., Hinwood A., 2016, Development of Land Use Regression models for particulate matter and associated components in a low air pollutant concentration airshed. Atmospheric Environment 144.p.69-78.

5. Greenland S., Finkle W.D., 1995. A critical look at methods for handling missing covariates in epidemiologic regression analyses. J. Epidemiol. 142 (12), p.1255-1264.

6. Guyet T., Nicolas H., 2016. Long term analysis of time series of satellite images. Pattern Recognition Letters 70 (2016).p.17-23.

7. Junger W.L., Leon A. P., 2014. Imputation of missing data in time series for air pollutants- Atmospheric Environment 102 (2015) p.96-104.

8. Juodis L., Filistovic V., Maceika E., Remeikis V., 2016. Analytical dispersion model for the chain of primary and secondary air pollutants released from point source. Atmospheric Environment 128.p.216-226.

9. Meraz M., Rodriguez E., Femat R., Echeverria J.C., Alvarez-Ramirez J., 2015. Statistical persistence of air pollutants $\left(\mathrm{O}_{3}, \mathrm{SO}_{2}, \mathrm{NO}_{2}\right.$ and $\left.\mathrm{PM10}\right)$ in Mexico City. Physica A 427. (2015).p.202-217.

10. MEU. Ministry of Environment and Urbanization. Air Quality Monitoring Network. web address: http://www.havaizleme.gov.tr/Default.ltr.aspx date: 11.02.2016.

11. Perepu S. K., Tangirala A. K., 2016. Reconstruction of missing data using compressed sensing techniques with adaptive dictionary-Journal of Process Control 47 (2016)p.175-190.

12. Poberznik M., Strumbelj E., 2016.The effects of air mass transport, seasonality, and meteorology on pollutant levels at the Iskrba regional background station (19962014). Atmospheric Environment 134 (2016)p.138-146.

13. Qu Y., An J., He Y., Zheng J. 2016. An overview of emissions of $\mathrm{SO}_{2}$ and $\mathrm{NO}_{\mathrm{x}}$ and the long-range transport of oxidized sulfur and nitrogen pollutants in East Asia. Journal of Environmental Science p.13-25. 